\title{
Interspecies Relationships: Death, Grief and Mourning in Bengali Short Stories
}

\section{Swatilekha Maity}

\begin{abstract}
This chapter will attempt to analyze how animal-human relationships have been represented in Bengali short stories through their depiction of death and mourning in its various forms. In analyzing this nuanced aspect of interspecies relationship, this chapter will attempt to locate the positionality of the animal in respect to the canonical, mainstream anthropocentric literary landscape. To a great extent, the expression of grief and mourning towards the companion beings has been shaped by the human perception towards the animal. This chapter will attempt to fathom this human animal dynamic through a multidimensional perspective sociocultural, economic and inter-personal relationships of alienated individuals. 'Disenfranchised grief' and its articulation in terms of companion animals functions as a crucial factor in this analysis. This chapter throws into the relief how significantly the inter-species communication in terms of gaze, speciesism and empathy construct a counter narrative of Postcoloniality in its inclusive, all-encompassing range.
\end{abstract}

Keywords: Death, Inter-Species Relationships, Animal Gaze, Companion Animals, Mourning

The animal- human relationship is interspersed with so many discourses in a multidimensional way. The relationship of human beings with their animal companions traces back to ancient times, when survival for the physical existence were deeper and prioritized (Lorenz, 2012, pp. 1-18). From memento-mori to various kinds of ritualistic social mores, death has made its presence across different cultures. In this chapter, I will attempt to how death can be considered as a bridge that forms a connection and communication between animals and human beings. It is a significant point how animals have always been allowed only a marginalised existence in mainstream literature. This marginalisation is often characterised either through their complete absence from the literary worlds, or their depictions which are imbued with a sense of passivity (Woloch, 2003, p. 38). Their contribution in shaping our perception towards the world as well as towards our own selves has been crucial in determining factors like notion of ownership, interspecies cohabitation and the position of human beings in this world.

Focusing on three short stories of Bengali literature, Samudrik (Of the Sea) by Sayd Mustafa Siraj, Brown Saheber Bari (Mr. Brown's Cottage) by Satyajit Ray and Kalapahar by 
Tarashankar Bandyopadhyay, I will attempt to address this transformative impact of death and the process of grieving in the history of interspecies coexistence. I will endeavour to draw the connecting points between the relationship of companion beings to their humans, cognizable presence of them in lives of us and transformative impacts of their deaths on human beings. I will argue that these stories function as crucial narratives in not only creating a space for these significant yet overlooked animal companions but also a transformative impact in animal-human bonding. The death functions a pivotal role in strengthening the bond rather than erasing it to oblivion and in this way, it signals at the deeper instinctive level of interspecies communication. In this paper, I attempted to see how the experience of losing a companion being has been articulated in the language of mainstream, canonical anthropocentric literary landscape. I have positioned these three stories in a way, which should demonstrate the journey of companion animals from the periphery to the centre, from a silent passive subject to independent, complete individuals. In this way, these stories perform a significant part in paying tribute to the animal beings, whose existence has mostly been forced into a silent obliteration.

\section{Gaze and Interspecies Communication}

Samudrik (Of the Sea) has been selected from a collection of supernatural stories, Tara Ashariri by Sayd Mustafa Siraj. The title of the story, i.e., Samudrik in Bengali language stands for anything which belongs to the ocean or is derived from the ocean. The entire story is told from a first-person narrator's perspective; the story is an account of the narrator's autumnal vacation by a small sea side town. This very brief story does not hesitate in addressing the importance of the natural backdrop and in this way subtly yet provocatively situates the narrator in a secondary position. The story recounts the interaction of the narrator with a girl and her small dog by the sea beach. The narrator informs us that he was invited to spend his autumnal vacation at the house of Dr. Prabhudayal Panigrahi in the small town of Chandanpur On Sea, a quasi-imaginary town situated by the Eastern region of India. From the very beginning of the story, the readers are confronted with a backdrop, which is dominated by nature. We learn that human interference in that small, remote town is minimal. From the very start of the story, there is a predominant notion about the centrality of this natural world with human beings at its periphery. The fear and intimidation that the narrator felt towards the sea, was aggravated by the lack of human interaction in the ambience, though the appearance of the little girl with her small dog altered his decision of leaving the town prematurely.

They were first introduced in the story at the second page of the account and from that point onwards, we see the focus has been shifted towards these two characters and their activities. Their presence and their interactions amongst themselves as well as with the waves of the sea, were presented to accentuate the self-absorbed and also self-sufficient nature of this relationship:

I was not finding the sea as terrible as before. Was it a little girl with her small, adorable dog, who changed the sea? I was observing them with enchantment. But they did not take me into consideration at all. (Siraj, 2017, p. 127) ${ }^{1}$

The narrator's gaze towards them was influenced by affection and enraptured. It is noteworthy how these two beings, both human and animal responded to the narrator's attempts to initiate a conversation, but their silent indifference was poignant. The narrator registers how his presence was unrecognized and seemingly silent to them:

I could not stay silent any longer. Told them, "' Tis enough. Come now, stop playing. Come to me. Let's talk among us. Hmm, what is your name? who is this little one,

\footnotetext{
${ }^{1}$ The excerpt sections of this story by Siraj, have been translated by me, as the English translations are not available yet.
} 
jumping and playing with you?"

Still, they did not look at me. I started approaching them laughing to myself and feeling amused. Then they started running on the beach. Is it also a game to them? Or are they getting scared of me? I shouted at them, "don't be afraid of me- I have nothing to scare you." (Siraj, 2017, p.127)

What was striking at this point of the story is that, the narrator is thoroughly conscious of their presence, a presence of a little girl with her very small, adorable companion dog, yet to them, his own presence was reduced to almost nonexistent, a blank. A very relatable presentation of so many animal characters or more specifically animal presence in mainstream canonical literature of the time. We come across animal characters either as an extended personification of human beings, of us in fables and folk tales. To a great extent, they are almost always mentioned in the backdrop, like the bark of a distant street dog in a depiction of a night scene or the call of a kite in some silent midday; in the works, where they were recognized with their own characters, are still quite few in numbers. This is where this story stands out by emphasizing on the irreplaceability of companionship between animals and human beings and accentuating their centered position with nature, aptly.

A major turning point occurs when the narrator is returned a glance from both the dog and the little girl. In this entire course of narrative, this interaction of gaze only occurs once. More specifically it is the gaze of the dog which was capable of articulating the expressions, the creating of a deep-rooted communication:

The little girl stopped skipping abruptly. Coming nearer to the girl, the dog lifted her face to me. Her eyes gleamed with moonlight and reflected it. With those amazing blue eyes, the dog seemed to observe me. The eyes of girl, were equally bright and glimmered with moonlight. (Siraj, 2017, p. 128)

The narrator notes that the girl seemed to reply something to his question but it was inaudible, incomprehensible and then they started running again:

She just smiled and then they started running again. I saw their silhouettes vanishing on the white, moonlit sand of the beach, gradually. I assumed, she may be mute, maybe she could not understand my language. (Siraj, 2017, p. 128)

In this predictable ghost story, the crux of the narrative hinges on this way of communication. The haunting presence of the young girl, Pinky and her dog Julie occupies a position of ambiguity as it may be intangible in comparison to the corporeal existence of the adult narrator, yet it has a dominant and deciding force, characterized through auditory and visual manifestations. Very ironically, when we see the narrator approaching them, it is the presence of this human, adult, male narrator, who is faced with a strong indifference almost reducing his presence to an invisible entity; in that way he became 'othered subject' in the eyes of these characters. It can be argued that in the scope of this story, the central position of the animal characters is a bit problematic, as their presence is contingent on their human companions. But the glance, the communication takes place across the boundaries of speciesism, across different dimensions of presence and most significantly, it is the glance of the companion animal, the soft, white, small dog whose gaze at the narrator registers the presence as well as the existence of the narrator. Berger in his Why Look at Animals, points out how amongst human beings linguistic system forms a fundamental system of communication. He continues:

With their parallel lives, animals offer man a companionship which is different from any offered by human exchange. Different because it is a companionship offered to the loneliness of man as a species. ( Berger, 1991, p. 6)

The equally empathetic understanding of this 'unspeaking companionship' underscores man's inability, incapability to speak to animals (Berger, 1991, p. 12). But this relationship across species and the power of the animal's gaze transforms this story into a dialogue with these marginal presences in literature. 


\section{Death and Beyond in Animal-Human Relationship}

This very notion of understanding among the species that also becomes a focal point in the next story of this paper, i.e., Mr. Brown's Cottage by Satyajit Ray. The plotline of the story follows the stylistic device of embedded narrative, where the first-person narrator comes across the diary of an English school teacher Mr. Brown from a second-hand book shop in College Street, Kolkata. The storyline follows a steady, linear narrative, which registers the details such as, the colour of the ink, number of pages and most significantly dates. This story is a poignant articulation about the loss of a cat and the human companion's psychological and emotional responses to his death. Throughout the course of the story, the details about Simon gradually construct his independent selfhood, as a being, as a person with distinctive preferences and choices. This construction of personhood determines the course of events and with this manipulation, Ray places this non-human being at the centre of the account. The story forces us to visualize and experience a reality of an interspecies relationship, that is rooted in the interdependence and mutuality rather than anthropocentric domination on other forms of life. a generalized overview of the storyline seems to suggest a parallel reference to Poe's The Black Cat from the perspectives of the association of supernatural presence of the black cat and its impacts on his human companion's life. Yet, this comparison is not only flawed but also extremely inappropriate. In that story, the black cat, Pluto came back as an agent of retribution for the crimes of the narrator. In Ray's this story, the animal-human bond functions as a connection, which even survives the separation of death.

In his diary, John Middleton Brown made references to his immediate surroundings as well as his own workplace, i.e., the school where he was a teacher, his early life at Sussex and the general description of Bangalore, even his late wife, named Elizabeth. His relationship with Simon was the closest and the strongest bond he had with anyone. Simon's favourite spot in the house to his particularly favourite chair, the diary is flooded with all the details of his character, like bravery, whim or courage. In the entire story, the readers are compelled to see him as a being without being limited of his species-specific identity. It is also a significant pointer that in the entire story, it was never mentioned that he was the pet cat of Brown. The intensity of Brown's grief for death of Simon on twenty second September, 1858, is articulated with a complete absence of any entry till second November, 1858.

Simon's reference in the diary returned on second November, when Brown saw his spectral presence looking at him from his favourite chair:

As soon as I stepped into the living-room, I saw Simon sitting by the fireside in his favourite high-backed chair! Simon! Was it really Simon? I felt overjoyed. Simon was looking straight at me with such affection in his eyes. (Ray, 2012).

This very notion of looking that also becomes a focal point in this story. The diary demonstrates the process of how 'micro-narratives' not only operate but also become equally important as the apparent major milestones in cultural history. These 'micro-narratives' throw into the relief the presence of marginal characters and beings, shaping and contributing to our lives, the coexistence and mutual understanding between non-human and human beings and the socio-cultural memories of these varied relationship. The diary records the visit of the Viceroy's wife, Lady Canning to Bangalore with tangential importance yet every whim and distinctive behaviour of Simon, a cat is depicted with minutiae details. I would argue that, in this way, the story construes the voices from the margin, as it prioritizes not only an ordinary person but also a cat, someone whose existence was considered outside the boundaries of anthropocentric purview. The initial responses of the narrator, Ranjan, his friend, Anik and Hrishikesh Banerjee, point at the presumptuous notion majority of the human beings possess 
and nurture; Hrishikesh Banerjee's exclamation, "So, Simon was a cat!" points at the human beings' ready assumption that any being with a name and having taken up a considerable part of any narrative, should be a human being. The story subtly works on these anthropocentric assumptions only to dismantle it at the very end:

Mr. Brown's Simon- that intelligent, whimsical, proud, devoted and affectionate

being whom he loved so well- was the black cat we had seen today! (Ray, 2012)

Weisman (1991) has established that grief consequent of the death of a companion animal can turn out to very overwhelming and distressing, as the relationship shared by both animal and human being is more authentic and enduring. The story raises a significant question of animal consciousness and their ability of experiencing separation; it underscores that the pangs of eternal separation isn't always limited to only among the human beings but also transcends the barriers of speciesism and can be felt by the companion nonhuman beings as well. Keddie (1977) contends that the overwhelming mourning can result in some pathological symptoms of intense grief, which stems from an intense dependence on pets and less reliable human interactions. Simon's spectral yet affectionate gaze towards his life long human companion, Brown even after his death, is a confirmation and articulation of a very unique and authentic relationship in the history of world literature. In this way, this story contributes to the mainstream narrative, a cognition and awareness of beings beyond the anthropocentric, spiciesist paradigm.

\section{Articulation of Grief and Mourning in Companion Being}

In the works of Tarashankar Bandyopadhyay are frequently interspersed with the convergence of interspecies communications. Multiple works like, Nari o Nagini (The Woman and the Serpent) and Nagini Kanyar Kahini (Tale of the Snake-Girl), Bedeni (The Serpent Woman) are very close studies in this animal human coexistence. But the experience of death in nonhuman beings along with their companion human beings has been depicted in Kalapahar in a very distinctive way. The story demonstrates a very complex relationships of human with animals, a relationship based around mutual dependence, sustenance, economic involvement and implications and most importantly a deep-rooted affection. Kalapahar should fall in the line of numerous works of literature, which deal with emotive experiences and attachments related to cattle and farm animals. Notable examples may include Bibhutibhushan Bandyopadhyay's Budhir Bari Fera (The Homecoming of Budhi), Munshi Premchand's Do Baillon Ki Katha (A Tale of Two Oxen), Sarat Chandra Chattopadhyay's Mahesh. The syntax and narrative stylistics of Kalapahar create a very poignant and intense experience of death not only amongst interspecies relationships but also intraspecies bonding as well.

This story, Kalapahar is a story of a buffalo, more specifically the loss of a buffalo to his fellow buffalo and their owner, a farmer.From the very beginning of the story, it was clearly mentioned that Ranglal is a farmer, who is deeply involved in the wellbeing of his cattle. The writer describes how Ranglal takes care of his cattle almost every day:

He hung a garland on the cow's neck with a string of bells, he rubbed all over its body twice day with torn jute clothes, he massaged the hons with oil; at times he even took care of its legs. If someday they worked too hard, Ranglal would say, "Ah, that's the animal that belonged to Lord Krishna!" (Bandyopadhyay, 2013)

Yet, the very next paragraph in the story described something contradictory, or rather superficial in his love for these animals. It seemed that Ranglal's affection and attraction was based around the physical grandeur of these beings: 
Only last year he bought a pair of cows but Ranglal had no compassion for them. The cows weren't small, neither could you call them of low breed. But many in this region had better cows than those. (Bandyopadhyay, 2013)

This outward seemingly superficial affection is significant as yet brought him closer to the buffaloes, Kalapahar and Kumbhakarna. It is noteworthy, how the third person narrator subtly infuses a connection of empathy in the readers while depicting the scenario of the cattle market. In the weekly gathering of Panchundi market, all the animals had a countable material worth with them. The buffaloes were huge in size and shape, but their precarious position and the interspecies violence perpetrated on them, left their traces both on the corporeal body as well as emotive existence:

The dark-skinned ferocious-looking animals were made to run all around without any respite... Some had lost their skin and you could see slimy red ulcers on them. (Bandyopadhyay, 2013)

The monstrosity of human beings with their tortures overpowered these gentle giants and coerced them into submission. It is significant, how the writer places Ranglal's spontaneous empathy beside the indifferent cruelty of cattle sellers. In this scenario of cruelty and indifference, Ranglal first encountered Kalapahar and Kumbhakarna. Ranglal's presence was able to express the empathy and mutual understanding shared between farmers and their cattle; the physical proximity, the shared struggles for survival and the economic dependence on this nonhuman beings can be traced back to these relationships. The economic aspect of this relationship is a significant pointer, as it emphasizes the intensity of love Ranglal felt for the buffalo, after the incident of his partner's death.

In this story, death is more tangible and real; unlike the other two stories I included in this chapter, Kalapahar stands out in its immensity and poignancy of the experience of death as perceived by both humans as well as nonhuman beings. The pivotal part of the story comes out with the appearance of a cheetah during their grazing by the river banks. It is an event which sets forth the other incidents consequentially. The encounters between buffaloes and the cheetah, which proved to be fatal for Kumbhakarna and the cheetah and for Kalapahar himself in the long run, also hints at another deep aspect of the contemporary scenario. This encounter underscores a narrative of interspecies violence which stems from the human intervention into the wild habitation. The narrative is punctuated by death several times; the death of Kumbhakarna, the cheetah, the young buffalo newly purchased by Ranglal for Kalapahar's companionship, the calf and most significantly, the tragic consequence of Kalapahar himself throws into the relief how grief as a psychological process leaves its repercussions in animal consciousness. The story positions a fundamental question through Kalapahar's immediate as well as long lasting responses to his companion's death. How do the animals experience grief?

Kalapahar's intolerance of any other animal in the place of his companion, Kumbhakarna, underlines his inability to accept any other being as the substitute of deceased Kumbhakarna. In this way, this specific behaviour consolidates their recognition and assertion of individualized selfhood as sentient beings. Taken in a symbolic level, Kalapahar's behaviour also counters the way animals are perceived as each other's substitutes. Kalapahar's position in the household is rooted as a tool for agricultural, juxtaposed his immense significance as a companion being; the material, expendable worth of his life is countered by his irreplaceable and important position as Ranglal's companion animal. Contrary to the popular belief, pet owners have confessed how the eternal childlike dependency and attention, the companion animals bring to a family (Beck and Katcher, 1996, 
p.42). The exclusive affection and trust that Kalapahar felt for Ranglal transcends the boundary of the corpus of spiciesist linguistic lexicon:

Ranglal came and stood near Kalapahar. The beast looked at Kalapahar with red and swollen eyes and then puts its face on to his lap. Ranglal began to rub its head with tender affection. (Bandyopadhyay, 2013)

Ranglal's repeated failures to sell him and Kalapahar's self-willed return juxtaposes the intensity of this interspecies bonding of Ranglal and Kalapaharwith the materialistic, profit based, exploitative relationships of whole sellers and cattle dealers. Even Ranglal's final act of leaving him to the other seller did not stem from materialistic maneuvering. Rather it was a plea on his part to manage an unmanageable reality, far beyond his grasp. Kalapahar's incessant cry, his aimless wandering in the market and his attempts to find his way to the place, he perceived as home, maps out the trajectory of emotional dependency on inter species level.

The story attempts to articulate an experience which transcends the ambit of our linguistic capacity and demonstrates an experience as unfathomable yet poignant as death and the eternal separation. Kalapahar's witnessed his companion Kumbhakarna's death, an experience which problematised and ruptured his position in an anthropocentric scenario. In a place, where loss of animal was not given space for acknowledgement, this story puts forth the question, if we can recognize and respect this sense of loss and grief in our companion beings. Unlike the other two short stories discussed in this chapter, death occurred in the present tense of the narrator, the impacts are more direct. Kalapahar's poignancy of grief is taken over by a gesture of mute anger; his expressions are vivid, non-verbal yet gripping. His own swift and lonely death by the shot of the police officer manages to incorporate the enigmatic yet misunderstood existence of his own life. In an essentially anthropocentric world, Kalapahar's grief was translated as 'heat' and his grief stricken, blind loyalty to Ranglal as 'madness'. The story is an endeavour to register the inexpressible, poignant by transforming our perception of death from a physical, tangible experience to a visceral, psychologically cathartic reality.

This chapter attempts to position these three stories as spaces, which create a foray into animal-human relationships. These three stories voice out the marginalised position of nonhuman beings in this anthropocentric mainstream literature. In this paper, we confront different modes of companion beings, the framed against an oceanic backdrop in the first story, the spectral in the second and the real in the third. Together these three stories construe a narrative of animal utterances in an area, where their position is always almost accentuated by their imposed passivity. These works construct a line of narrative, which not only acknowledges the animal presence but also compels their independent, individual dynamic and contribution in the validation of human existence. The concept of this chapter dawned on me in the International Conference on re-thinking postcolonial. Reinterpreting the texts also entails a way of reading the texts from an inclusive perception, which will encompass the experiences beyond gender, race, caste and most significantly speciesism, as Rajamannar puts it, that, "human animal distinction is the most foundational hierarchy of human thinking and practice, providing the most basic 'ism' that underlies all other forms of discrimination."(Rajamannar, 2012, p. 6). This chapter attempts to create a space for this marginalised 'vanishing animal bodies' (Lippit, 2000, p. 1) by locating the centered presence of animals in Bengali short stories. This chapter intends to establish how these short stories initiates a point of inclusion by an act of articulation of 'disenfranchised grief' (Doka, 2008). 


\section{References}

Bandyopadhyay, T. (2013, October). Kalapahar (S. Ray, Trans.).

http://www.bengalitranslator.net/blogliterary/kala-pahar-tarashankar-Bandyopadhyayshort-story-in-translation/

Beck, A. M \& Katcher, A. H. (1996). Pets are family. Between pets and people: The importance of animal companionship (pp. 40-62). Purdue University Press.

Berger, J. (1991). Why look at animals? About looking (pp. 3-28). Vintage Books.

Doka, K. J. (2008). Disenfranchised grief in historical and cultural perspective. In M. S. Stroebe, R. O. Hansson, H. Schut, \& W. Stroebe (Eds.), Handbook of bereavement research and practice: Advances in theory and intervention (pp. 223-240). U. S. Psychological Association.

Keddie, K. (1977). Pathological Mourning after the Death of a Domestic Pet. British Journal of Psychiatry, 131(1), 21-25. http://doi:10.1192/bjp.131.1.21

Lippit, A. M. (2000). Introduction: Remembering animals. Electric animal: Toward a rhetoric of wildlife (pp. 1-26). University of Minnesota Press.

Lorenz, K. (2012). How it may have started. Man meets dog (pp. 1-18). New York: Routledge.

Rajamannar, S. (2012). Introduction: Why the animal? Or, can the subaltern roar, and other risky questions: Some theoretical frameworks. Reading the animal in the literature of the British raj ( pp. 1-16 ). Palgrave Macmillan.

Ray, S. (2012). Mr. Brown's Cottage (G. Majumdar, Trans.). Satyajit Ray: The collected short stories [Kindle android version]. (Original work published in 1971). Penguin Books.

Siraj, S. M. (2017). Samudrik. Tara ashariri (pp. 126-129). Dey's Publishing.

Weisman, A. (1991). Bereavement and companion animals. Omega Journal of Death and Dying, 22, 241-249.

Woloch, A. (2003). Introduction. The one vs. the many: Minor characters and the space of the protagonist in the novel (pp.1-42). Princeton University Press.

\section{Bio-note}

Swatilekha Maity has completed her B. A. and M.A. in English from the University of Calcutta and completed her M.Phil. in English from Jadavpur University, India. Currently she is a $\mathrm{PhD}$ Candidate in the Department of English, Jadavpur University, India. Her areas of interest include travel writing, Nineteenth Century, the practice of ethics in animal rights and human-animal coexistence in cultural studies.

Email id: - maityswatilekha@gmail.com 